\title{
El valor histórico del pituto: clase media, integración y diferenciación social en $\mathrm{Chile}^{1}$
}

\author{
nan \\ EM M AN U ELLE BAROZET \\ Departamentos de Sociologíay CienciaPolítica de laU niversidad de C hile
}

\begin{abstract}
::: R ESU MEN
Existe entre los miembros de la clase media chilena una práctica muy anclada, Ilamada intercambio de favores, que permite obtener bienes y servicios mediante vínculos amistosos. Partiendo de la afirmación que la raíz de esta forma orgánica de solidaridad se confunde con el nacimiento de la clase media a principios del siglo XX , planteamos que dicha práctica ha evolucionado posteriormente con las macro transformaciones sociales y económicas que ha sufrido el país. En este artículo, se describe el intercambio de favores, con una doble mirada: la primera, histórica, sobre su conformación y la segunda, sociológica, sobre las lógicas que animan, hasta el día de hoy, esta forma de solidaridad social.
\end{abstract}

PA LA B R A S C L AV E : intercambio de favores, clase media, integración social.

::: ABSTRACT

This article deals with a practice deeply rooted in the social life of the $C$ hilean middle class : the exchange of favors which, through reciprocity and friendship ties, insures access to diverse types of goods and services. A large array of socio-historical analyses has established that this form of organic solidarity findsits social originsin the very formation of the middle class at the turn of theTwentieth century. I argue here, however, that this practice was affected by macro-sociological processes of social change that significantly transformed it in the course of the following decades. The article describes, analyzes and explains reciprocity through a double historical and sociological lense, examining the various logics at work in this form of social solidarity.

K EY W O R D S: reciprocity, middle class, social integration.

\footnotetext{
${ }^{1}$ Este artículo recoge los resultados de una investigación llevada a cabo entre 1997 y 2002, en base a 40 entrevistas semiestructuradas con miembros de los estratos sociales medios en Santiago. Se realizaron además períodos de observación participante en espacios de trabajo en varias instituciones chilenas. La actualización de los datos se enmarca en el proyecto Fondecyt 1060225. A gradezco los comentarios deV icente Espinoza y M aría Luisa M éndez, aś como el trabajo editorial de R odrigo Baño.
} 
En estemomento, por ejemplo, yo observo mucho en lamentalidad del chileno el rodearse de muchosamigos pedir favoresy hacer favores Eso escomo unasuerte de compromiso, unacadenaqueno se corta. ${ }^{2}$

No, paramí, el asunto de losfavoressiempreesparte de la cultura en este país. Esparte de lacultura. Buenao mala, pero esun patrón de comportamiento arraigado. iA todo nivel! ${ }^{3}$

Para quienes trabajan acerca de la clase 4 media chilena, existen hoy interrogantes respecto de su tamaño y de sus características sociales, después de las transformaciones macro sociales que desarticularon la capa media conformada antes de los años 60. Los procesos económicos que marcaron estas transformaciones son conocidos, al igual que sus consecuencias en los sectores populares, pero respecto de la mesocracia chilena, la visión sigue siendo, hasta cierto punto, borrosa.

U n elemento llama particularmente la atención respecto a una de las formas de capital ${ }^{5}$ de la cual dispone la clase media en comparación con otros sectores: el «pituto», también llamado compadrazgo o favor. Se trata de una manifesta ción extremadamente eficiente del capital social. Esta práctica, que llamaremos aquí «ntercambio de favores», es una forma de reciprocidad entre individuos de un mismo círculo o nivel social, que permite, mediante vínculos informales, mantener una solidaridad orgánica entre cercanos. ${ }^{6}$ Se trata de una práctica masiva, determinante e indispensable para obtener un trabajo 0 bienes y servicios, a los cuales no se podría tener acceso debido a las limitaciones de los servicios públicoso del mercado, a menos que se recurra a la personalización de los vínculos y la instrumentalización de las redes personales. D escansa en la conformación de lazos de confianza amistosa y está vinculada a la forma en que, a lo largo del siglo XX, se fue desarrollando la clase media, que opera como agente histórico de redistribución del Estado.

\footnotetext{
${ }^{2}$ Entrevista con M. 66 años, recaudadora del C olegio M édico.

3 Entrevista con V., 39 años, abogado de la U niversidad de Chile, empleado de la Superintendencia de servicios sanitarios.

${ }^{4}$ La elección del término «clase» responde a la necesidad de referirnos de manera clara a grupos sociales determinados. Esto no implica necesariamente enmarcarse en un enfoque neomarxista, pues las virtudes y flexibilidad del término clase han sido demostradas en los análisis de estratificación. T iene además la ventaja de no centrarse solamente en variables como la categoría socio profesional, el ingreso o el estatus: incluye una reflexión acerca del impacto de lasposiciones sociales en las experiencias, conductas y prácticas de losindividuos, siendo el último punto de particular interés en este trabajo.

${ }^{5}$ Según la clásica tipología de B ourdieu, existen varios capitales; el capital económico, el capital cultural, el capital simbólico y el capital social.

${ }^{6} \mathrm{~N}$ o estamos hablando de una singularidad de la sociedad chilena en cuanto a solidaridad orgánica. El intercambio de favores es sin lugar a dudas un universal antropológico y existe en todas las latitudes, con distintos rasgos, importancia y peso en la vida cotidiana. N uestra meta en este trabajo consiste en aislar sus rasgos y analizar su peso histórico en la vida social de las clases medias chilenas, así como establecer su importancia en tanto elemento de integración, pero también de diferenciación social.
} 
Proponemos en este trabajo describir y analizar el intercambio de favores, con el fin de entender el peso que tiene en la vida social de los chilenos y chilenas de clase media.También examinaremos hasta qué punto se puede considerar, dentro de los análisis de estratificación social, como uno de los elementos distintivos de este grupo. Sostendremos que el desarrollo de la clase media chilena a partir de 1920, al alero del crecimiento estatal, significó que uno de los mayores dispositivos de integración social del cual se benefició este grupo, ha sido y sigue siendo el intercambio de favores, que permitía el tránsito de bienes y recursos desde el Estado hacia ese sector, consolidando su posición respecto a los sectores populares. Este elemento de integración se adaptó a la posterior jibarización de las agencias estatales en los años 70 y 80, que llevó a un reordenamiento de la práctica del favor, pero en ningún caso a su desaparición.

En una primera parte, describiremos las características generales de este mecanismo de redistribución de riquezas y de preservación del estatus de la clase media tradicional chilena. Luego, examinaremos las razones de la aparición del intercambio de favores, práctica que se confunde con el crecimiento de la clase media, con el fin de entender cómo afecta la estructura y la cultura relacional de las capas medias. En una tercera parte analizaremos el elemento estratégico que determina el estatus de la clase media: su estrecha relación con la estructura estatal, para luego analizar la influencia que ejerce este elemento en la sociabilidad de la clase media. Veremos después cómo se diversifican las fuentes de los intercambios de favores a partir de los años 80 mientras se fracciona la antigua clase media. En la última parte, expondremos las características del intercambio de favores en términos de redes y las razones que explican hasta hoy su eficiencia.

\section{El pituto como intercambio de favores: de la importancia estructural de una práctica de solidaridad orgánica}

$\mathrm{H}$ ace más de tres décadas, antes de la U nidad Popular, la antropóloga mexicana Larissa Lomnitz, hacía notar que entre los chilenos y las chilenas de clase media existía una práctica muy anclada y a la cual buscaba encontrar significado: el pituto, favor, ${ }^{7}$ 0, como se llamaba entonces, el compadrazgo (Lomnitz, 1994: 1946). Consiste en una forma de regulación social, entre la economía de mercado y la redistribución de parte del Estado. que perdura como un intercambio constante y sistemático de asistencia, ayuda, apoyo entre familiares, amigos y conocidos. Se capitaliza como una deuda simbólica, que genera una reciprocidad importante y obligatoria. Lomnitz atribuía en ese entonces una notoria importancia a este intercambio, ${ }^{8}$ que según ella podía ser considerado como el recurso

${ }^{7}$ Por favor, se entiende un intercambio de «servicios» entre dos personas, a primera vista voluntario, desinteresado y espontáneo. Su naturaleza depende en la mayoría de los casos del lugar que los individuos involucrados ocupan en la estructura social.

${ }^{8}$ Evidentemente existen sistemas de ayuda mutua informal en otros grupos sociales en $C$ hile. Sin embargo, las redes de las clases populares fueron mucho más estudiadas y fueron incluso el objeto de un importante trabajo de acción social, como estrategia de superación 
estratégico del cual disponía el sector medio chileno y que le permitía asumir un papel de mediación entre sectores obreros y élites. A firmaba incluso que se trataba de un «criterio crucial para la membresía dentro de la clase media» (Lomnitz, 1994: 19). Pero más notoriamente, sigue siendo hasta el día de hoy una práctica social institucionalizada, ${ }^{9}$ debido a su extensión y permanencia en el tiempo.

En palabras de uno de los entrevistados, «un pituto es conocer a al guien que trabaje adentro de algo, de una institución, de una empresa y que te puede ayudar 0 que te puede conseguir alguna información o te puede facilitar alguna... pero es... va por ese lado digamos....». ${ }^{10} \mathrm{D}$ e manera más precisa, Lomnitz lo define como «un sistema de reciprocidad que consiste en el intercambio continuo de favores que se dan, se reciben y se motivan dentro del marco de una ideología de la amistad» (Lomnitz, 1994: 23). A unque hoy en día los favores no son sólo de naturaleza burocrática - por los cambios ocurridos en la estructura estatal bajo la dictadura y la privatización de gran parte de los servicios públicos - aún permiten obtener no solamente un trabajo, sino que también un gran número de bienes y servicios (permisos, documentos, préstamos, cuidados médicos, revisión técnica del auto, inscripción de un niño en un colegio, exención del servicio militar, por ejemplo) que no se pueden conseguir por las vías más formales o más institucionales a causa de las carencias de los sectores públicos y privados. ${ }^{11}$

A pesar del sentido que adquiere la palabra en $C$ hile, cabe recordar que el «compadrazgo», en su definición más precisa, es una práctica social común a muchos países latinoamericanos y se puede considerar como un lazo fundamental de las relaciones sociales en A mérica Latina. ${ }^{12}$ A unque Lomnitz usa el término compadrazgo para describir la ayuda mutua informal que existe en el seno de la clase media chilena durante los años 60, preferimos llamar este fenómeno «ntercambio de favores», pues la autora utiliza la palabra compadrazgo en un sentido mucho más amplio que el que se usa en otros países y puede generar

de la pobreza.V éase D idier (1986) y E spinoza (1995). Por otro lado, si bien existen sistemas de ayuda mutua en las clases acomodadas chilenas, el interés de un estudio en ese sector es mucho más limitado, puesto que tienen un poder adquisitivo suficiente como para obtener los bienes y servicios mediante compra y no por el intermedio de otras personas.

${ }^{9}$ La palabra «nnstitución» aparece todavía hoy de manera espontánea en el discurso de varios entrevistados.

${ }^{10}$ Entrevista con A., 35 años, ingeniero de soporte.

${ }^{11}$ Para quienes viven en regiones, la centralización estatal también es un obstáculo.Trámites que se resuelven en días o semanas en Santiago pueden extenderse mucho más por la lejanía y complejidad del sistema central.

${ }^{12}$ En antropología, el compadrazgo se define como una «relación de coparentezco espiritual, que instituye entre las personas lazos de intercambio y de obligaciones [... ] y donde la función principal parece ser la constitución de una red de alianza segura» (Lavaud, 1976: 105). Se refiere en general a la relación que existe entre el padrino y la madrina de un niño, y en un sentido amplio, a la relación que existe entre los padres de un niño y aquellos que asumen el rol de padrino y de madrina. 
confusiones en la actualidad. En efecto, si bien el tipo de lazo que describimos aquí posee puntos comunes con el compadrazgo en su sentido antropológico, existen suficientes diferencias entre estas dos prácticas como para utilizar términos distintos. Por ejemplo, el intercambio de favores se da entre amigos y conocidos y no se limita a intercambios entre padrinos y padres de un niño. Según Lomnitz, «El compadrazgo [chileno] es esencialmente una relación personal entre individuos que se consideran de igual nivel social. Según un informante, los compadresse reclutan entre «parientes, miembros de un mismo partido político, amigos, conocidos de un mismo nivel social, amigos de amigos, compañeros de trabajo, miembros de una logia masónica, o en general, gente que comparte las mismas aspiraciones intelectuales, una misma ideología política, o intereses similares en la vida» (Lomnitz, 1994: 29-30). A demás, el uso de este término era efectivamente amplio en los años sesenta en el lenguaje hablado en C hile, mucho más que en la actualidad. A cambio, el término «ntercambio de favores» permite destacar la especificidad de la relación en C hile y corresponde a la vez a la denominación local actual: se trata por lo tanto de una relación continua entre dos personas, amigos o conocidos, que comúnmente se hacen favores. EI término no se refiere solamente al momento preciso de la transacción, sino que al tipo de relación que se establece entre las dos personas.

\section{La construcción de la clase media chilena: factores históricos de diferenciación social}

Para entender el anclaje histórico de esta práctica, cabe remontarse a la aparición de la clase media chilena, puesto que el intercambio de favores es consustancial a la formación de ésta. La fuerte composición mesocrática de la sociedad chilena entre losaños veinte y sesenta ${ }^{13}$ es un rasgo significativo de la historia social y cultural del país y este peso favoreció la difusión del intercambio de favores.

La clase media chilena se empieza a desarrollar al final del siglo XIX, en el momento de la expansión salitrera posterior a la anexión de las provincias del $\mathrm{N}$ orte y el consecuente desarrollo comercial. Las cuentas del Estado se abultan en ese entonces con los impuestos provenientes de la minería. Estos cambios impulsan una transformación de la estructura económica y social del país, abriendo espacios para nuevos sectores sociales, so bre todo para las «nuevas» capas medias. La «clase media antigua», según los términos de Filgueira y G eneletti (1981), ${ }^{14}$ estaba hasta el momento constituida casi exclusivamente por profesiones independientes, artesanos, pequeños propietarios y trabajadores del comercio. Pero la macro tranfformación que sufre el país conlleva una evolución en este grupo social: su crecimiento no proviene de la movilidad social de grupos populares ni de la expansión de la antigua clase media, pues esta «nueva clase media» está

\footnotetext{
${ }^{13}$ La clase media llega en los años sesenta a conformar el $40 \%$ de la población (véase Pinto et al., 1972).

${ }^{14}$ Graciarena (1967), por su parte, usa la terminología «clases medias residuales» y «clases medias emergentes».
} 
compuesta sobre todo por funcionarios y empleados de la estructura estatal. ${ }^{15}$ Esta transformación de la estructura social se puede medir por cierto desde un punto de vista cuantitativo, pero quizá más importantes son los cambios cualitativos que se dan en este nuevo grupo social.

Sin embargo, la crisis del salitre obliga a un cambio de modelo de desarrollo. Los programas sociales de lucha contra el desempleo implementados durante la dictadura de Ibáñez del Campo (1927-1931), así como las medidas proteccionistas que buscan estimular la economía, beneficiaron sobre todo a la naciente clase media burocrática, gracias al creciente corporativismo del Estado, mediante el cual el Presidente pretende lograr una salida a la crisis. En esta época, el cuerpo administrativo aumentó notablemente, debido a la falsa bonanza económica que permite al Estado desarrollar su capacidad de reclutamiento. Sin embargo, la Gran D epresión barre rápidamente los esfuerzos del gobierno. Lleva a una fuerte contracción de las remuneraciones, pero no a una reducción del empleo público: «D urante las décadas de 1920 a 1950 la clase media creó una burocracia poderosa y bien organizada, que sirvió inicialmente para fortalecer las iniciativas del desarrollo económico, pero que luego se convirtió en una baluarte de privilegios y en un mecanismo para perpetuar el goce del poder administrativo por parte de un grupo social bien definido» (Lomnitz, 1994: 20).

Posteriormente, después de la segunda guerra mundial y de la crisis del modelo de desarrollo implementado en los años treinta, el aumento de la demanda por productos mineros chilenos abre una nueva fase de prosperidad y un nuevo período en la industrialización del país. El Estado sigue sosteniendo el esfuerzo de inversión. N o obstante, la creciente dependencia frente a los mercados externos y los casos más numerosos de corrupción fragilizan el crecimiento, así como la estabilidad social y política del país. La inflación vuelve, los salarios dejan de crecer y un fuerte malestar social se instala, sobre todo en el seno de la clase media. M ientras, ésta sigue creciendo al inicio de los años cincuenta, a raíz del aumento de las responsabilidades del Estado y del grado de complejidad de sus funciones, sobre todo en el ámbito industrial y el comercio. Hasta los años sesenta, ambos sectores económicos reciben un fuerte apoyo de parte del Estado, que busca la industrialización a cualquier precio, a pesar de las dificultades recurrentes que enfrenta desde los años cuarenta. En un contexto de creciente carencia económica y de estancamiento de los sueldos, el desarrollo desmedido de la administración pública aparece como una forma de cooptación social y de limitación de los conflictos entre sectores sociales.

Aunque no se estructuren como un solo conjunto social, existen algunos rasgos que permiten en esta primera fase a los miembros de la clase media chilena identificarse, sino como pertenecientes a un grupo específico y relativamente homogéneo, por lo menos como cercanos los unos con los otros y sobre todo, diferentes a la vez de los sectores populares y de los sectores acomodados. D esde los análisis de estratificación social, los criterios que se suelen emplear

${ }^{15}$ La inmigración, aún importante en la primera mitad del siglo xx , será una de las fuentes de esta expansión. 
son los siguientes: el carácter urbano de este grupo social, las profesiones y empleos que le son característicos y consecuentemente sus niveles de ingreso, y el acceso a la educación pública.

Primero que nada, durante ese período de expansión social, la clase media se caracterizan por su carácter más bien urbano. En efecto, la urbanización empieza de manera temprana en Chile, ${ }^{16}$ debido al auge del salitre, que acelera la decadencia de parte de la agricultura. Se trata de un elemento central para este grupo, también relacionado con el segundo criterio, el empleo, pues adicionalmente se puede definir a la clase media en términos de ingresos 0 de estatus socio económico. La clase media en esta época está compuesta por burócratas, funcionarios del Estado, y profesionales en general como expresión de la «nueva clase media», pero también por artesanos, pequeños productores y comerciantes, como representantes de la «antigua clase media». El patrimonio no es tomado en cuenta como una dimensión determinante, contrariamente a lo que ocurre en Europa en el mismo período para este grupo social, pues el capital económico de la clase media chilena tiene severas limitaciones y su patrimonio es reducido. ${ }^{17}$ Por lo tanto, la clase media cuenta solamente con sus ingresos por concepto de sueldo, ${ }^{18}$ lo que la acerca a los sectores populares más que a los sectores acomodados. Incluso, los ingresos del sector medio bajo son muy inferiores a los del sector medio alto, generando en este tramo una fuerte vulnerabilidad social.

En tercer lugar, la clase media se diferencia por su fuerte aspiración a la movilidad social mediante la educación pública. La educación, es de hecho uno de los elementos centrales de la alteración cualitativa que sufre este grupo, en especial en el caso chileno. La cobertura de la escolarización se amplia a partir de los años veinte, pero después de la segunda guerra mundial, se da un significativo aumento del número de años de escolarización. En los años cincuenta y sesenta, la enseñanza secundaria y universitaria aumenta para el sector medio, pero sin que la tasa de analfabeti smo se reduzca para los sectores populares, pues este crecimiento no está acompañado de un nuevo aumento de la cobertura de la enseñanza básica, en especial en el campo. Es por esta razón que el bajo acceso a la educación puede ser considerado como un rasgo distintivo de los sectores populares y que la referencia a la educación pública es esencial para entender la identidad de la clase media chilena. A través de ella, se adquiere no solamente conocimientos y un diploma, sino que valores fundamentales para la identidad del grupo, al igual que un capital social determinante para la vida adulta y profesional: si bien el contenido de la formación tiene en sí una importancia

${ }^{16}$ La tasa de urbanización en Chile pasa de 30,6 \% (con 2,5 millones de habitantes) en 1885, a 76\% (con 9,3 millones de habitantes) en 1970 (A rellano, 1985: 24).

${ }^{17}$ En este grupo social, el ahorro casi no existe; existe más bien una tendencia al endeudamiento. (véase Lomnitz, 1994).

${ }^{18}$ Los sectoresmedios burocráticos vieron sus salariosmejorar en un 46\% entre 1940 y 1953, los sectoresmediosindependientes en un 60\%, mientras para los obreros, el aumento alcanzó solamente 7\% (véase Pinto, 1962). Sin embargo, la inflación merma gran parte de esta alza. 
fundamental, lo que las familias mesocráticas val oran es el conjunto de los contactos que los niños y jóvenes tejen durante su vida escolar y que conservarán a lo largo de su vida. Por otro lado, el acceso a la educación crea nuevos mecanismos de reproducción social, que favorecen a la clase media: en los años 60 se consolida la brecha entre sectores medios y sectores populares, pues éstos pueden demostrar en promedio tres años de escolarización. A cambio, en la clase media, los sectores menos afortunados tienen un promedio de 8 años de escolarización versus 11 para los sectores medios acomodados (Filgueira y G eneletti, 1981) y cuando a partir de los años 60 los sectores populares acceden a la educación primaría completa, los sectores medios ya terminan la enseñanza secundaria 0 entran a la universidad pública, manteniendo el diferencial educa tivo con los sectores menosacomodados. Pero quizá lo más sorpresivo es que los sectores medios logran incluso sobrepasar a los sectores acomodados en número de años de escolaridad:

Tabla 1. Niveles promedio de educación en Chile 1960-1970 (número de años de escolarización)

\begin{tabular}{|c|c|c|c|c|c|c|}
\hline \multicolumn{7}{|c|}{ ESTRATOS SOCI OPR OFESI ONALES } \\
\hline Año & $\begin{array}{c}\text { Empleadores y } \\
\text { personal de } \\
\text { dirección }\end{array}$ & $\begin{array}{c}\text { Profesiones } \\
\text { intermedias }\end{array}$ & $\begin{array}{c}\text { Comerciantes } \\
\text { independientes, } \\
\text { vendedores, } \\
\text { empleados }\end{array}$ & $\begin{array}{c}\text { Clases } \\
\text { populares, } \\
\text { sector } \\
\text { secundario } \\
\text { (obreros) }\end{array}$ & $\begin{array}{c}\text { Clases } \\
\text { populares, } \\
\text { sector } \\
\text { terciario }\end{array}$ & $\begin{array}{c}\text { Clases } \\
\text { populares, } \\
\text { sector } \\
\text { primario }\end{array}$ \\
\hline 1960 & 8,9 & 10,8 & 8,1 & 4,9 & 3,8 & 2,5 \\
\hline 1970 & 9,1 & 11,8 & 8,7 & 5,2 & 4,6 & 3,1 \\
\hline
\end{tabular}

Fuente: C. Filgueira (1976), Expansión educacional y estratificación social en América Latina, 1960-1970, Buenos Aires, Cepal. En gris destacamos los sectores que corresponden a la clase media en los análisis de los autores.

Esta ventaja que tiene el sector mesocrático, incluso sobre los sectores acomodados, si bien no se traduce mediante mejores ingresos y genera entonces una inconsistencia de estatus, sí le significa un capital cultural elevado y un capital social muchas veces indefectible a lo largo de su vida. En consecuencia, si bien ni el capital educacional, ni la categoría socio profesional aseguran cierto nivel de ingreso para el sector mesocrático, la clase media compensa en parte su diferencial de ingreso con los gruposacomodados mediante el prestigio asociado a las profesiones intermedias o que requieren de varios años de estudios universitarios.

Sin embargo, siendo entonces su nivel de ingreso y de educación bastante bajo, los miembros de la clase media asegurarán de otra manera su ascenso social y la estabilidad de su estatus, gracias a las ventajas que obtienen de su relación con el Estado mediante el intercambio de favores. ${ }^{19}$ En efecto, más allá de los

${ }^{19}$ Estos elementos conformaron una clase media homogénea en términos de variables sociales, pero también en términos de identidad, lo que constituye una situación bastante excepcional en América Latina, pues las diferencias étnicas, religiosas, culturales o de profesión son limitadas en C hile. 
criterios tradicionales mencionados anteriormente, existe otro criterio de diferenciación social: el acceso a ventajas corporativas entregadas por el Estado, que permiten consolidar fuertemente el estatus de la clase media: el acceso a la seguridad social, así como a diversos tipos de ayuda pública, beneficia primero que nada a la clase media (M iranda, 1994). Entramos aquí al análisis de un elemento no solamente relacional, sino que derechamente organizacional, pues el desarrollo de un Estado benefactor potente a partir de los años 40 y sus lógicas de redistribución favorecen al grupo mesocrático, en términos de acceso a la salud, a las pensiones y a subvenciones diversas. D esde los años 1890 y más claramente a partir de 1920, el Estado se hace progresivamente cargo de la condición sanitaria del país, bajo la presión de la «cuestión social» que nutre el debate político. A partir de los años 40 , gracias a la creación de las $C$ ajas de Previsión para los funcionarios públicos y los empleados privados, y luego del Servicio M édico N acional de Empleados en 1942, los miembros de la clase media tienen un acceso privilegiado a la salud.A partir de los años 50 , el sistema de protección aumenta en cobertura, pero no está exento de disfunciones graves, lo que deja a los sectores populares fuera de su red de protección. La clase media, gracias a sus contactos en la estructura estatal, se encuentra particularmente favorecida, pues si no tiene acceso directamente a los cuidados médicos, puede conseguirlos gracias a su capital social. O curre lo mismo con el sistema público de pensiones, particularmente favorable para el sector medio. ${ }^{20}$

Si añadimos a este panorama un conjunto de subvenciones, como subsidios para la vivienda, o beneficios como colonias de vacaciones para los niños o casa de reposo para los ancianos, obtenemos un conjunto de beneficios no monetarios, que mejoran considerablemente la vida cotidiana de este estrato. Sin embargo, estas ayudas están sujetas a importantes variaciones, ${ }^{21}$ pues no se trata de beneficios constantemente y estructuralmente asociados con la condición de empleado público, sino que deben ser continuamente renegociados con los funcionarios de los ministerios, quienes se ven presionados para extenderlos a otros grupos familiares. Esta extensión de las formas de cobertura social «personalizadas» por sector de empleo público termina en una especie de proliferación de los beneficios excepcionales (Sunkel, 1971). El tipo de ventajasque los miembros de este grupo obtienen de parte del Estado son muy superiores

${ }^{20}$ C omo los grupos que ejercen una presión más fuerte sobre la administración pública tienen un acceso privilegiado al sistema de pensiones, la clase media se encuentra particularmente favorecida en este aspecto. El sector obrero, que no pertenece a la clase media y que representa un $75 \%$ de quienes cotizan, recibe una pensión equivalente a la mitad de lo que reciben los empleados del sector privado y al $7 \%$ de lo que reciben los empleados del sector público, quienes sí son de clase media. Esto muestra el diferencial del aporte y del beneficio de los sectores obreros y medios respecto al acceso a pensiones. Además, los obreros deben trabajar hasta los 65 años, mientras que los empleados públicos pueden jubilarse después de 30 años de servicio en esa época (Pinto, 1962).

${ }^{21}$ Entre las agencias estatales más privilegiadas, se puede mencionar el Parlamento, el Banco Central, el Banco del Estado y el M inisterio del Interior. 
en comparación con los sectores populares: esta situación también permite al sector mesocrático constituirse como clase, gracias a elementos objetivos que los diferencian de otros grupos sociales.

\section{El pituto como práctica estratégica: la estrecha relación entre el crecimiento de las clases medias y la estructura estatal}

$R$ especto al período de crecimiento de los sectores medios, el intercambio de favores consiste en «azos de ayuda recíproca, cuidadosamente administrados y dosificadoss (De la Peña, 1994: 7). Se destaca el peso determinante de las conexiones políticas en el seno de la burocracia chilena y la importancia que éstas adquieren en la construcción de un bienestar material relativo. Exploraremos en esta parte las bases de esta afirmación: el empleo público primero y luego las conexiones políticas que determinan la sociabilidad de los sectores medios antes de la dictadura.

C uriosamente, a pesar de que el peso del Estado sea considerado como determinante no solamente en la conducción económica, sino que también en la formación de movimientos sociales o de los partidos políticos, existen muy pocos estudios históricos sobre el sector público en $\mathrm{C}$ hile e incluso se ha tendido a despreciar al personaje del funcionario público (Jobit, 1951). Sin embargo, la implementación del Estado paternalista favorece en el caso chileno sectores precisos, cuyo poder y estatus en la estructura social - como lo mencionamos - están basados en la redistribución controlada de los recursos que gestionan en nombre del aparato público.

En los años 20, los argumentos a favor del estatismo en el continente descansan en la necesidad de proteger la incipiente industria nacional de la competencia internacional, lo que desemboca en la creación de organismos públicos crediticios o de fomento, la mayoría de los cuales seguía existiendo en 1973. A demás, la clase media conforma justamente el grupo que puede absorber los productos industriales, debido al mercado que conforma. En consecuencia, el Estado suele ser el primer empleador a nivel nacional. Se trata de un fenómeno común en la región, donde la «burocratización prematura» es el resultado «de la expansión del empleo administrativo estatal, derivada de la creciente importancia del sector público en la promoción del desarrollo» (M artínez y Tironi, 1985: 11). Pero en Chile, la tasa de crecimiento del Estado en términos de masa salarial es superior a la de los otros sectores e incluso, en países como Brasil, U ruguay o Chile, la expansión del sector público y particularmente de la administración, es superior al crecimiento de la población activa. En el caso de Chile, la expansión burocrática es particularmente dinámica: el total de empleos públicos pasó de cerca de 30000 en 1925 a casi 120000 en 1967 y a 325000 en 1975.22 Entre 1938 y 1970, el empleo público centraliza-

${ }^{22}$ Arturo Alessandri ya era calificado de «maniaco del empleo» (véase U rzúaValenzuela y García Barzelatto, 1971). 
do ${ }^{23}$ habría aumentado en un 3,8\% anual, es decir 3 veces el crecimiento de la masa salarial total (M uñoz, Gatica y R omaguera, 1980: 14). A pesar de los cambios de gobierno, la tendencia se mantuvo, ${ }^{24}$ para estabilizarse en los años sesenta, lo que confirma una absorción estructural de determinados sectores de parte del Estado. Esta nueva tendencia corresponde a la insuficiencia del crecimiento económico durante los años cincuenta. La lógica de expansión del sector público deja por completo de reflejar las necesidades de empleo público del país. Corresponde entonces a la incapacidad del sector privado de crear puestos de trabajo a un ritmo adecuado, así como al carácter marcadamente paternalista del Estado. Se da además en un contexto de creciente dificultad para la economía del país. Existe por lo tanto una fuerte contradicción entre un Estado omnipresente pero que hace malabarismos con recursos insuficientes por un lado, y un conjunto de mecanismos de redistribución gracias a un sistema que descansa en lealtades políticas por otro lado.

$R$ ecordemos que este sector público no está sometido a las mismas reglas que el sector privado, lo que significa que la lógica de su expansión no depende ni de la competencia económica, ni de la maximización de la producción. Incluso no existe un estatuto unificado del funcionario, pues cada organismo estatal tiene sus reglas y sus beneficios propios. Según M artínez y T ironi (1985), el sector que más creció no fue la administración general del Estado (R egistro Civil, Correo y Carabineros entre otros), sino que precisamente los servicios sociales como la educación y la salud, además de las actividades de fomento de la economía (M O P,V ivienda y C orfo). ${ }^{25}$ Este elemento es crucial para entender qué tipo de ventajas tienen los miembros de la clase media: el acceso directo a los servicios que provee el Estado mediante empleo público. De hecho, de los 325000 funcionarios que tiene Chile en 1975, justo antes de su jibarización, más de la mitad pertenecen al sector «social» del Estado.

Se trata en el fondo de un «sistema de prebendas y privilegios que configura una forma redistributiva por excelencia» (Filgueira y Geneletti, 1981: 78), pues si bien existen criterios normativos en los ministerios y las agencias del Estado, éstos se engarzan con las leal tades políticas de los electores, quienesintercambian bienes públicos contra sus votos. En la clase popular, es a través del clientelismo que se puede establecer una relación en forma particular con la estructura esta-

${ }^{23}$ El sector público centralizado corresponde a las instituciones públicas que dependen directamente del gobierno central y no tienen autonomía respecto a éste (véase M uñoz, Gatica y R omaguera, 1980: 7 y siguientes).

${ }^{24}$ Se dieron dos intentos de reforma del sistema público: en 1945 (regulación del número de funcionarios y del monto de los salarios) y al final de los años 50 durante el mandato de Jorge Alessandri (racionalización del funcionamiento del sector público y control de los gastos), pero no fueron eficientesni lograron cambiar las prácticas dentro del sector público. La tercera reforma, propuesta por Frei M ontalva, no se concretará por falta de apoyo de la oposición.

${ }^{25} V$ éase en anexo el crecimiento del sector centralizado, por funciones, así como el gasto público del sector social para los años 1935-1983 (véase también Muñoz, Gatica y R omaguera, 1980). 


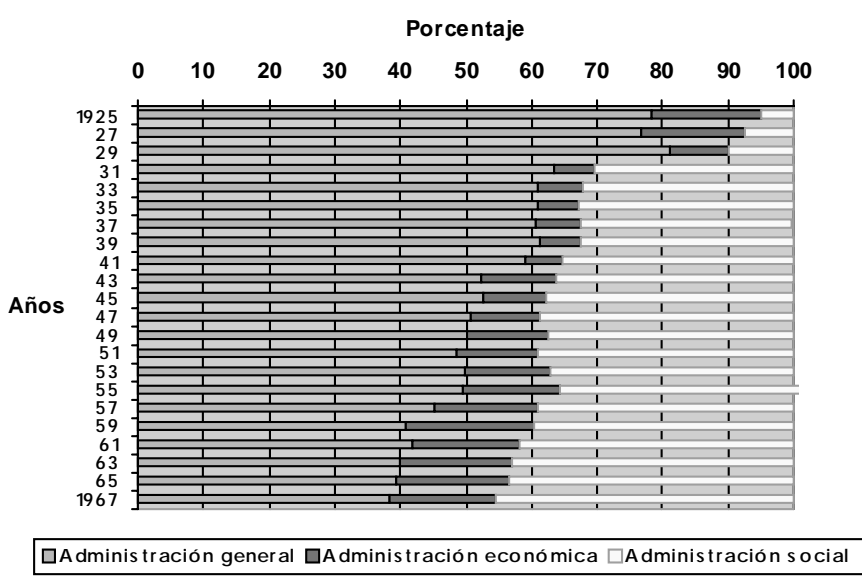

Gráfico 1. Número de funcionarios por sector en la función pública entre 1925 y 1965.

Fuente: Elaboración propia a partir de Rehren (2001: 20).

tal, pero de manera vertical (es decir con una marcada desigualdad entre quien pide el favor y quien lo hace), mientras que en la clase media, los bienes y servicios se pueden conseguir por la vía del empleo público, pero de forma horizontal (relativamente de igual a igual). D e esta manera los miembros de la clase media logran tener acceso para sí, sus familias, sus amigos y sus conocidos, a beneficios que el propio sistema público demora mucho en entregar o no entrega si no se usan redes personalizadas de contacto. ${ }^{26}$

Finalmente, en términos de empleo, el hecho que los miembros de la clase media sean en general empleados públicos se explica por el sistema de reclutamiento, que depende exclusivamente de las vinculaciones personal es de quienes ya están insertos en la estructura estatal, razón por la cual familias enteras trabajan al servicio del Estado, aunque lo hagan en agencias distintas. Este fenómeno de cooptación pasa entonces a ser el elemento que permite una fuerte movilidad social para importantes grupos sociales chilenos, en particular para la clase media. $^{27}$

Por otro lado, en el capital social de los sectores medios, pesan las vinculaciones políticas. En efecto, la creciente urbanización, así como la transformación de las estructuras de producción del país favorecen la implementación de un sistema partidista temprano en la historia chilena. Los partidos tienen además una

${ }^{26}$ Para ver las consecuencias políticas de este fenómeno y el papel de intermedio que ejerce la clase media en losaños sesenta en el sistema de representación política, véaseValenzuela (1977).

${ }^{27}$ Esta dinámica propia del mundo de los funcionarios, también se extiende en parte a los miembros de la clase media que trabajan en el sector privado (pequeños comerciantes, pequeños empresariosque se benefician de las política de fomento, profesiones independientes o asalariados del sector privado que educan a sus hijos en la educación pública), pues también compiten para las subvenciones que ofrece el Estado, aunque acceder a ellas no sea tan directo como para los funcionarios. 
importante cobertura nacional, lo que no es común en la región. Este sistema será un verdadero motor de integración política para las nuevas capas medias: el desarrollo de los partidos políticos en Chile, al igual que en Argentina, es un indicador del crecimiento de la clase media (R emmer, 1984: 58-59). A demás, el sistema partidista chileno ha sido un factor notable de estabilidad para este grupo social, ${ }^{28}$ al darle un acceso permanente a los espacios de poder, aunque no le permita conseguir la hegemonía política.

Los historiadores señalan con frecuencia la elección deA rturo Alessandri a la Presidencia de la $\mathrm{R}$ epública como el momento inicial del apogeo de la clase media, pues durante los años veinte y treinta, este sector pesa fuertemente en los comicios y se puede pal par su influencia en cada uno de los mandatos presidenciales de la época, en especial gracias al papel de «tercera fuerza» que desempeña el Partido R adical (véase G arcía Covarrubias, 1990: Lomnitz y M elnick, 1998; Sunkel, 1971). «La clase media creció al alero del radicalismo, paralelamente al crecimiento de la burocracia y a los vínculos cada vez más estrechos con las instituciones de gobierno. En otros palabras, la clase media nació en la medida que se fue ligando con la burocracia y que se fue ligando ipso facto al partido [radical]»(U rzúaValenzuela, 1968: 158). Éste recoge los votos no solamente de la clase «media media», sino que también de los sectores medios que colindan con los sectores populares. Esta imbricación entre PR y clase media urbana es tan fuerte que Johnson (1958) considera que se puede estudiar de manera paralela su crecimiento. En el período 1940-1955, la influencia de la clase media llega a su culminación y su peso sobre la vida política es más notoria (Fal etto y R uiz, 1970): los Presidentes Pedro Aguirre Cerda (1938-1941), Juan Antonio R íos (1941-1944) y Gabriel González Videla (1946-1956) pertenecen al PR . $\mathrm{H}$ asta el día de hoy, el gobierno de A guirre Cerda simboliza en la memoria nacional el periodo de mayor poder de los sectores medios. Sin embargo, los radicales no lograrán captar la totalidad del voto de clase media, puesto que la extrema izquierda y la extrema derecha constituyen una al ternativa política para una minoría de sus miembros. Esto significa, entre otros elementos, que el grupo medio no logrará obtener el control total de las instituciones, pues no conseguirá la mayoría política, al contrario de lo que ocurrió en varios países europeos en la misma época. La clase dominante tradicional ejerce en este mismo período una fuerte oposición a las ambiciones mesocráticas, por lo que los sectores medios siempre deberán buscar apoyos en otros grupos sociales, sea en los sectores populares asalariados o los terratenientes, según lo ameriten las circunstancias. Por lo tanto, aunque se instale una mesocracia radical en Chile, siguen pesando los valores tradicionales de los terratenientes, quienes logran mantener su hegemonía simbólica sobre el sistema social y político chileno.

En los años cincuenta, el PR se acerca a la derecha, mientras pierde poder debido a la integración de nuevos sectores populares a la vida política. El estan-

${ }^{28} \mathrm{Al}$ principio del siglo $\mathrm{xx}$, esta incipiente tendencia ya se nota en el poco aumento de los poderes del ejecutivo, mientras el poder legislativo absorbe nuevas funciones, lo que a su vez refuerza el papel de los partidos políticos. 
camiento del PR será compensado en la clase media por el desarrollo de la D emocracia C ristiana, creada en 1957 (Fleet, 1985; García C ovarrubias, 1990: Lomnitz y M elnick, 1998). El centro radical tradicional y pragmático cede su lugar a un partido doctrinario opuesto a las coaliciones, que adquiere el papel de principal partido mesocrático en $\mathrm{C}$ hile. Pero este traspaso partidista de los sectores medios no logra eclipsar su pérdida de centralidad en el sistema político chileno, debido al incremento demográfico de los grupos populares. En los años 60 , la política apunta tardíamente a la integración de estos abultados contingentes sociales, pero el sistema económico y político del país se desestabiliza. EI auge de los sectores medios terminó: la extensión a otros grupos sociales menos favorecidos de los derechos sociales que consiguió en las décadas anteriores, cuestiona los beneficios de la clase media. Sin embargo, a pesar de este declive, logra preservar las características de su identidad y de su sociabilidad, creadas en las décadas anteriores, al mantener la ventaja que le significa su capital social, reforzado por una fuerte sociabilidad de clase. En palabras de Lomnitz, «un funcionario político usa su situación en la burocracia para hacer numerosos favores a sus amigos: exenciones de multas de tránsito, permisos municipales, empleos en la burocracia provincial, pensionesy fondos de retiro, etc.» (Lomnitz, 1994). C apitaliza estos favores para obtener otros elementos a cambio y para consolidar su posición social y su estatus.

\section{La sociabilidad de clase media: la red de circulación de los favores}

En términos de su sociabilidad, la clase media está en contacto con un conjunto de organizaciones e instituciones entre los años veinte y sesenta, que favorecen su representación política e influencian fuertemente su comportamiento relacional. La estructura partidista es efectivamente determinante para entender cómo se construyó su identidad, pero en un plano mucho más informal, las relaciones que se tejen entre funcionarios y sus familias en base al intercambio de favores generan una red de protección, en especial alrededor de los clubes radicales, presentes a lo largo del país. ${ }^{29}$ La casi ausencia de trabajos de investigación acerca de la sociabilidad partidista - o simpatizante- en esos años limita las conclusiones que se puedan sacar al respecto. Sin embargo, la importante afiliación de la clase media al PR es el elemento formal e ideológico (además de las vinculaciones familiares ya mencionadas) que le abre en grande las puertas del empleo público, pues al ser radical, el postulante a un empleo público no tenía que dar el examen de competencias: así, durante los años cincuenta, cerca del $70 \%$ de losmilitantes radicales trabajan en la función pública(R ehren,2001). EI PR es sin lugar a dudas el partido que mejor encarna la cohesión identitaria

${ }^{29}$ Se trata de un espacio de sociabilidad permanente y familiar. M uchas veces tienen salas de lectura y de juegos, además de salas de reuniones para los miembros y los simpatizantes del partido. A pesar de la centralidad de este lugar de sociabilidad, no hemos hasta el momento encontrado estudios que permitan desarrollar este punto. 
de la clase media, empalmada con lugares de sociabilidad donde se superponen las relaciones familiares, amistosas y de vecindario. En la década siguiente, con la DC suplantando el PR, las lealtades partidistas se transfieren en parte de una formación a otra, pero repitiendo el mismo patrón de sociabilidad. De hecho, en ambos partidos, prevalece el igualitarismo, en base a un importante apego a la amistad (Lomnitz y M elnick, 1998). En cuanto al «recluta medio» de la DC, en palabras de Alan Angell, «el democratacristiano 'típico' no es el burócrata del gobierno del periodo anterior, el maestro de escuela o el abogado de provincia que formaban el corazón del PR. Es más probable que sea miembro de la clase media urbana profesional, trabajador calificado o director, lo que corresponde a los grupos que surgieron gracias a la diversificación de la economía en los veinte últimos años» (1974: 189). También su relación con la I glesia es mucha más cercana, creando otro espacio de sociabilidad, pues la I glesia «equivale» al club radical, incluso con una ideología cercana en términos de solidaridad de clase.

Por otro lado, los sindicatos ${ }^{30}$ de funcionarios y oficinistas tienen un fuerte poder de movilización y ofrecen importantes espacios de sociabilidad: los sindicatos de docentes primero ( $\mathrm{N}$ úñez, 1956) o la U nión de Empleados de $\mathrm{C}$ hile y luego los sindicatos de la salud pública y del Correo son sin duda los más activos, al igual que la AN EF, creada en 1943, a la cual 150000 personas están afiliadas en los años 60. En 1948, la Confederación de Empleados de Chile acoge a su vez a losmiembros de la clase media que trabajan en el sector privado (Angell, 1974) Sin embargo, no existe una relación directa entre sindicatos de clase media y PR, e incluso los primeros se opondrán al gobierno, debido a que la inflación merma sus salarios. Solamente al final de la década del sesenta, los sindicatos de oficinistas se acercan a la C entral U nitaria de Trabajadores (CUT), pero manteniendo su cultura legalista y la defensa de las ventajas adquiridas por la clase media. U na vez más, el espacio sindical, al igual que los partidos políticos, es ideal para el intercambio de favores, debido a que los sindicatos son fuertes redistribuidores de beneficios públicos y sobre todo enérgicos defensores de las ventajas adquiridas.

Estas características son el sustento del capital social de la capa media en esa época. Por lo tanto, la gestión de los recursos públicos y el uso del capital social explican el estatus social que se alcanza en las capas medias, por sobre el capital económico, bastante mediocre cuando se considera el nivel de sueldos. Es más bien mediante el pedido y la devolución constante de favores a los amigos y colegas que los miembros de la capa media logran mantener cierto status socioeconómico. Incluso, la especial conformación de la sociabilidad mesocrática en torno al PR y luego a la DC, o alrededor de los sindicatos, genera reglas de comportamiento, de reciprocidad, formas de cortesía e incluso formas de lenguaje. Garretón describe de la manera siguiente las consecuencias de la extensión de la vida partidista a muchosámbitos de la vida social en losaños cincuen-

${ }^{30}$ Para el conjunto de los sectores de producción del país, la tasa de sindicalización es del $12,1 \%$ de la fuerza de trabajo en 1952, del 11,4\% en 1969 y sube al 23,3\% en 1970 (M artínez y Tironi, 1985). 
ta: se trata de sadherir a un partido en el cual el militantismo es casi religioso, con códigos internalizados que abarcan el conjunto de la vida militante, donde el partido lo es todo para el individuo y donde «a razón de Estado» se confunde con la «razón del partido». Como el militantismo es una especie de estilo de vida, la política pierde su carácter secular y se crea cierta tendencia a instrumentalizar el resto de las esferas de la vida social»(1987: 199).

En resumen, la sociabilidad de clase media, muy activa y basada en sentimientos de amistad, pero no exenta de cierta instrumentalización, se traduce por una política del favor hecho, recibido y devuelto; se trata de una visión muy concreta de la solidaridad, pero coronada a nivel normativo, en palabras de Lomnitz, por un «mperativo categórico» (Lomnitz y M elnick, 1998: 177): la política de la amistad o «amiguismo» ya está implementada fuertemente en las redes sociales mesocráticas. C on la polarización por la cual atraviesa el país hacia el final de los años sesenta y al principio de los años setenta, estos círculos se vuelven más necesarios, y más cerrados. La capacidad de acceso a los bienes y servicios depende entonces más que nunca de la capacidad de presión sobre el Estado.

\section{La diversificación de los intercambios de favores hoy como respuesta a la mayor heterogeneidad de la clase media chilena post años 80}

La clase media logra su máximo desarrollo entre los años cuarenta y cincuenta. Sin embargo, la integración de las clases populares en el sistema político a partir de los años sesenta conjuntamente con la radicalización política, llevan a un desequilibrio estructural que significa el retraimiento de la clase media a un segundo plano. Pierde entonces el rol articulador que adquirió en los años veinte. C on la dictadura, según fenómenos ampliamente estudiados y conocidos, se reduce considerablemente el tamaño del Estado y las capas medias sufren una profunda desestructuración, bajo el doble impulso de la militarización de la vida civil y la privatización de los servicios públicos (la «desburocratización», en términos de $M$ artínez y Tironi ${ }^{31}$ ), lo que genera recorridos sociales descendientes en gran parte de este grupo. Si bien surge en esa época un nuevo conjunto de profesiones independientes, se trata de actividades transicionales que responden a la precarización del empleo. $\ll \mathbb{E}$ I incremento general de las posiciones independientes revela una resignificación del mercado como mecanismo de articulación de los intereses sociales de clases y grupos, en perjuicio de diversos tipos de articulación burocrática (especialmente la mediada por el Estado) o política» (M artínez y Tironi, 1985: 111) En términos de remuneraciones, se nota un aumento de los ingresos de algunos sectores de la clase media con profesiones

${ }^{31}$ En 1968, el gasto fiscal correspondía al 21,1\% del PGB y ascendió al 44,1\% en 1973 , pero en 1979, ya había bajado nuevamente al 22,9\%; en este último período (1973-1978), el empleo público se reduce en un $25 \%$, lo que corresponde a un promedio anual de $-4,6 \%$ (véase M artínez y Tironi, 1985: 59-68). 
independientes y la disminución sistemática de los ingresos de los trabajadores manuales y de los sectores asalariados que conforman las clases medias medias y bajas. Este fenómeno significa una clara inversión de la tendencia dominante del siglo $X X$.

Tabla 2. Estratos sociales e ingresos individuales, 1972-1994 (en dólares US del año 1994) 32

\begin{tabular}{|l|c|c|c|c|c|c|}
\hline Clase/ Grupo socioprofesional & 1972 & 1976 & 1982 & 1986 & 1990 & 1994 \\
\hline Propietarios de grandes empresas & 772 & 996 & 2090 & 959 & 2046 & 2223 \\
\hline Propietarios de Pymes & 330 & 336 & 536 & 337 & 562 & 499 \\
\hline Profesionales & 500 & 429 & 932 & 522 & 705 & 654 \\
$\quad$ Profesiones liberales & 356 & 298 & 632 & 350 & 484 & 589 \\
$\quad$ Ingenieros & 649 & 579 & 1317 & 747 & 1056 & 728 \\
\hline Clases medias & 188 & 131 & 258 & 158 & 234 & 289 \\
$\quad$ Profesiones calificadas del comercio & 166 & 114 & 252 & 149 & 219 & 304 \\
$\quad$ Profesiones calificadas de los servicios & 232 & 173 & 352 & 211 & 323 & 335 \\
$\quad$ Profesiones manuales calificadas & 155 & 112 & 198 & 130 & 181 & 249 \\
\hline Clases populares & 116 & 76 & 151 & 97 & 145 & 199 \\
$\quad$ Profesiones no calificadas del comercio & 191 & 135 & 246 & 147 & 196 & 235 \\
$\quad$ Profesiones no calificadas de los servicios & 86 & 57 & 130 & 81 & 124 & 179 \\
$\quad$ Profesiones manuales non calificadas & 115 & 70 & 127 & 89 & 141 & 190 \\
\hline Promedio & 170 & 156 & 303 & 193 & 318 & 361 \\
\hline
\end{tabular}

Fuente: Koch (1999: 14)

C omo lo muestra la tabla, los ingresos de importantes sectores medios fluctúan fuertemente en función de los altibajos de la economía, además de disociarse entre los grupos medios bajos y los grupos medios altos.

A pesar de los pronósticos de Lomnitz acerca de la probable desaparición del compadrazgo en el caso de una reforma del Estado, y a pesar de este cambio drástico de la estructura política y económica del país, el intercambio de favores se mantuvo como una práctica muy presente y determinante para comprender los espacios relacionales de la clase media y las estrategias de adaptación, sean personales, más a menudo familiares o de grupo. En efecto, en esta fase de descomposición y posterior recomposición social, las redes de ayuda se vuelven aún más determinantes en algunos ámbitos, en especial para la obtención de un empleo, de un alojamiento, de cuidados médicos en el nuevo sistema 0 de préstamos intrafamiliares, en aumento en ese momento. Los estudios realizados sobre y desde esta época muestran que los círculos sociales se reducen drásticamente, muchas veces al entorno familiar y a los amigos más cercanos, es

${ }^{32} \mathrm{El}$ autor establece esta repartición sobre la base de la posesión o no posesión de bienes de producción y luego diferencia a los asalariados en función de su nivel de educación.También desagrega en otra tabla esta información en función del sexo, lo que arroja datosinteresantes acerca de las diferencias de género, sobre todo considerando que la fuerza de trabajo está compuesta por 2/ 3 de hombres y 1/3 de mujeres (véase Koch, 1999: 13). 
decir a vínculos fuertes (Lomnitz y M elnick, 1991; PN U D, 1998; M éndez, 2002; Granovetter, 1982).

Las transformaciones económicas de los años 70 y 80 significan que el gasto público se reduce a la mitad de lo que era a principios de los años 70, más de 400 empresas públicos son privatizadas y se expulsa a cerca de 100000 funcionarios del aparato estatal entre 1973 y 1978. Se trata de una de las transformaciones más importante que sufre el país en ese momento ( $M$ artínez y T ironi, 1985). A fecta sobre todo las agencias públicas ligadas al fomento de la economía y a los servicios sociales. Bajo el concepto del fortalecimiento de las libertades individuales, de la racionalización y mayor eficiencia de los comportamientos, se quiere «destruir el mito de la justicia social, al reemplazarla por el principio de la igualdad de oportunidadess (T ironi, 1998: 69). Con este horizonte, se transforman las relaciones laborales, el sistema de financiamiento de las pensiones, de la educación, de la salud: para la clase media, desaparece el marco de estabilidad del cual se había beneficiado durante décadas y los subsidios que le habían permitido mantener su estatus.

La importante diversificación que sufren los sectores medios en Chile en los años ochenta, asociada con una profunda ruptura de su identidad, de sus símbolos y de sus recursos, lleva a considerar incluso que este grupo se desvaneció, desagregándose hacia los sectores populares mediante pauperización por un lado 0 ascendiendo hacia los sectores acomodados para quienes se beneficiaron de los procesos de reestructuración de la dictadura. Es por esta razón que hablamos de clase media en singular antes de los años setenta y en plural después de esta década, asumiendo de esta manera su mayor heterogeneidad en las últimas décadas, y sobre todo la diversificación de sus identidades. ${ }^{33}$

En el ámbito de la sociabilidad de clase, el cierre de los partidos políticos, de los sindicatosy la vigilancia que se establece sobre la vida social desestructura las antiguas redes, dejando grupos enteros fuera del acceso a beneficios. Sin embargo, al poco tiempo, las redes sociales se reorientan, en la medida que el entorno económico y político obliga a las familias y a los individuos a rediseñar sus estrategias de inserción social, luego de una primera fase de derrumbamiento de las solidaridades tradicionales. La liberalización económica del sistema y el mayor incentivo a la individualización no logran descomponer las solidaridades orgánicas de las capas medias: les obliga a moldearse frente a la nueva realidad, adaptándose en parte a un sistema de movilidad individual. Sin embargo, el intercambio de favores sigue operando fuertemente. ${ }^{34}$

33 Sin embargo, como lo mencionamos anteriormente, varios autores usan el plural para distinguir las nuevas clases medias de las antiguas a partir de los años 20, como es el caso de Filgueira y Geneletti por un lado y Pinto (1962) por el otro, entre otros. A mbas referencias están en la bibliografía final.

${ }^{34}$ En las entrevistas, que fuera aplicadas de manera semi estructurada, se pudo establecer la importancia del uso del intercambio de favores en el recorrido personal, familiar y profesional de diversosmiembros de las clases medias. C on quienes ya habían iniciado su vida laboral antes de la dictadura o la iniciaron en ese periodo, pudimos explorar la reestructuración de 
C uando la estructura social se estabiliza nuevamente, en los años 1983-1985 y sale de la inestabilidad propia de los periodos de crisis o de transición estructural, nuevos principios de cohesión social emergen. A parece una conformación diferente de los grupos sociales:

Tabla 3. El espacio socio profesional: repartición cuantitativa de la población activa en comparación con las clases sociales (\%)

\begin{tabular}{|l|c|c|c|c|c|c|}
\hline Clase/ Grupo socioprofesional & 1972 & 1976 & 1982 & 1986 & 1990 & 1994 \\
\hline Propietarios de grandes empresas & 1,0 & 1,4 & 1,4 & 1,7 & 2,5 & 2,3 \\
\hline Propietarios de Pymes & 10,5 & 10,0 & 9,7 & 8,4 & 8,8 & 9,3 \\
\hline Profesionales & 6,2 & 7,3 & 9,0 & 11,6 & 11,8 & 13,4 \\
$\quad$ Profesiones liberales & 3,9 & 3,9 & 5,0 & 6,6 & 7,2 & 7,2 \\
$\quad$ Ingenieros & 2,3 & 3,4 & 4,0 & 5,0 & 4,6 & 6,2 \\
\hline Clases medias & 37,8 & 35,0 & 36,6 & 33,0 & 34.6 & 35,4 \\
$\quad$ Profesiones calificadas del comercio & 7,8 & 7,2 & 12,4 & 9,5 & 9,3 & 9,4 \\
$\quad$ Profesiones calificadas de los servicios & 16,5 & 14,9 & 12,4 & 11,4 & 12,3 & 12,5 \\
$\quad$ Profesiones manuales calificadas & 13,5 & 12,9 & 11,8 & 12,1 & 13,0 & 13,5 \\
\hline Clases populares & 44,5 & 46,2 & 43,3 & 45,3 & 42,3 & 39,6 \\
$\quad$ Profesiones no calificadas del comercio & 7,8 & 8,2 & 9,8 & 9,3 & 8,9 & 11,2 \\
$\quad$ Profesiones no calificadas de los servicios & 16,1 & 20,6 & 19,8 & 20,4 & 17,7 & 14,6 \\
$\quad$ Profesiones manuales no calificadas & 20,6 & 17,4 & 13,7 & 15,6 & 15,7 & 13,8 \\
\hline Total & 100 & 100 & 100 & 100 & 100 & 100 \\
Población activa (en miles) & 972 & 1009 & 1069 & 1335 & 1613 & 2001 \\
\hline
\end{tabular}

Fuente: Koch (1999: 11).

El reacomodo de los sectores medios ${ }^{35}$ no ha sido el objeto de estudios académicos específicos de estratificación después de los años noventa, por lo cual contamos solamente con datos de mediados de esta década. ${ }^{36}$

$R$ especto a la recomposición de las redes de sociabilidad, después de la primera frase de constricción al rededor de los vínculos fuertes, las redes se vuelven

sus redes sociales bajo el impacto de las nuevas condiciones políticas, sociales y económicas. Introducimos además un análisis en términos de ciclo vital para entender la conformación y el uso de sus redes de parte de los entrevistados.

${ }^{35}$ Para más detalle sobre las características de cada nuevo estrato medio, véase Bazoret (2002: 114 y siguientes).

${ }^{36} \mathrm{~A}$ cambio, los estudios de marketing han desarrollado herramientas de medición de los grupos sociales en $\mathrm{C}$ hile sobre la base de dos variables, entre las cuales educación, elementos residenciales o posesión de una determinada batería de bienes. Pero estas mediciones, si bien son precisas para los grupos más pobres y más acomodados, no permiten dar cuenta con exactitud de la diferenciación dentro de los sectores medios (C2, C 3 y D según la clasificación ESO M AR ), de losgrupos mayores y rurales. Pero a grosso modo, podemos hoy distinguir varios grupos medios en función de criterios de ingreso y nivel educacional, como corte grueso: las capas medias-bajas (con un ingreso familiares de $\$ 200.000$ a $\$ 400.000$, y educación secundariacompleta e incluso técnica superior), las capas medias medias (de $\$ 400.000$ a $\$ 1.000 .000$, muchas veces con formación técnica o universitaria completa) y las capas medias altas (sobre $\$ 1.000 .000$, con educación universitaria completa, incluso con posgrado). 
a abrir, con una fuerte recomposición de la práctica del intercambio de favores, que persiste hasta el día de hoy. La permanencia de este fenómeno puede ser considerada como una compensación y un modo de regulación relacional en un mundo de creciente precariedad. Estamos frente a un mecanismo informal de solidaridad social que sobrevive a las grandes crisis y alteraciones de los modelos de desarrollo. Bajo la dictadura y la vuelta a la democracia, como antaño, sirve fundamentalmente para mantener cierto grado de seguridad gracias a la solidaridad de los miembros de las redes en las cuales se está inserto. Este mecanismo de cohesión social de las clases medias es particularmente eficiente frente a las tendencias centrífugas de la economía, pues el intercambio de favores estabiliza ciertas tensiones del sistema gracias a una forma prediscursiva de negociación solidaria. Pocas veces se menciona que la permanencia de este fenómeno opera como una lógica distinta (sino opuesta, por lo menos resistente) frente al discurso y a las prácticas neoliberales que acompañan la transformación de la economía y de la sociedad chilena. Pero si bien la articulación burocrática ha sido minimizada, se crean nuevos tipos de articulación, cuya meta también es la protección de intereses grupales.

\section{¿R elaciones por sobre el ingreso? $M$ ás vale un buen amigo...}

En los párrafos anteriores, mostramos cómo el estatuto de la clase media tradicional chilena depende de mucho capital social y poco capital económico. Pero para mantener estas ventajas grupales, no basta el acceso individual a algunos servicios que provee el Estado y luego el mercado: debe existir un sistema tácito de ayuda mutua extensible al conjunto de este estrato social. En efecto, los círculos sociales familiares, por muy extendidos que sean, no permiten cubrir la gama de beneficios que necesitan los hogares medios, por lo cual la ayuda que pueden proveer los amigos y conocidos se torna fundamental en las estrategias individuales y grupales. Se genera una red extensa e informal de servicios, que permite activar distintas conexiones según los obstáculos que surgen debido a la carencia de recursos y a la lentitud de la resolución de los trámites burocráticos tanto públicos como privados. En este aspecto, la capacidad de negociación de cada uno o de su grupo familiar depende directamente de la posición social que ocupa y de la red de relaciones en las cuales está inserto. Según el tipo de empleo que se tiene y el tipo de bien o servicio que se puede redistribuir o intercambiar, se obtiene bienes equivalentes suministrados por otros servicios de la administración pública o del sector privado, mediante amigos y conocidos. A finales de los años sesenta, Lomnitz lo formulaba de la manera siguiente: $« \mathbb{E I}$ miembro de la clase media debe encontrar el mayor número de amigos con colocaciones estratégicas en los distintos niveles de la administración pública y privada: es absolutamente necesario, entonces, extender la red de parientes incorporán dole a amigos, parientes de amigos, y amigos de amigos. A sí cada miembro de la clase media ocupa el centro de una red extensa de relaciones personales interconectada por lazos de parentesco y amistad»(Lomnitz, 1994: 32). Esta frase sigue igualmente válida hoy. 
En términos de círculos solicitados, los grupos conformados en etapas tempranas de la vida, tanto familiar (parentela extensa) como escolar o universitaria son los más citados por los entrevistados, con rituales ${ }^{37}$ de mantención de los vínculos en las diferentes edades, mediante reuniones familiares, llamadas telefónicas periódicas, correos electrónicos o tarjetas de navidad, pero sobre todo informándose constantemente del devenir de los demás en todas las ocasiones sociales que lo permiten: se puede activar el vínculo años después del último encuentro y no parecerá extraño hacerlo, debido a la fuerza de la socialización inicial. En otras palabras, la eficiencia del intercambio de favores está relacionada con la antigüedad de las vinculaciones sociales. Posteriormente, los círculos profesionales pasan a ser una gran fuente de favores para quienes trabajan. ${ }^{38} \mathrm{EI}$ cultivo de la amistad desde la infancia y en las etapas posteriores es estratégico para tener en la vida adulta una red amplia y diversificada que suministra favores estratégicos. Estos círculos se mantienen en un plano bastante informal, aparte de los espacios profesionales y notamos que las vinculaciones no se dan en general a través de asociaciones: las clases medias urbanas presentan hoy una baja tasa de asociatividad, en comparación con los estratos populares y el mundo rural. Sin embargo, cabe destacar el papel que juegan los espacios deportivos y religiosos, que suelen también superponerse con los círculos familiares 0 amistosos. Pero esto no es en ningún caso comparable con la asociatividad formal de la antigua capa media de la primera mitad del siglo XX. ${ }^{39}$

En lo que se refiere a la eficiencia del intercambio de favores, aún hoy en día, en los sectores medios, las redes tienden a ser densas y multiplejas. ${ }^{40} \mathrm{En}$ primer lugar, como las relaciones son activadas regularmente o mantenidas a distancia, cada uno sabe en cada momento donde trabajan los otros miembros de la red. Esto se traduce mediante un reflejo que consiste en informarse acerca de donde trabajan los demás, del nombre de la empresa, en qué puesto, etc. Se entiende la importancia estratégica de este tipo de información, pues mediante ella se obtendrán informaciones o canales específicos para conseguir recursos. La segregación escolar, universitaria y espacial en Chile tiende además a homogeneizar

37 « so el término «ritual » porque se trata de actoscuyo componente simbólico muestra hasta qué punto la persona que actúa es digna de respeto o hasta qué punto estima que las otras personas son dignas de este respeto» (Goffman, 1974[1967]).

${ }^{38} \mathrm{C}$ abe notar aquí que existe una fuerte diferencia de género en este aspecto, pues la fuerza de trabajo en $C$ hile sigue siendo mayoritariamente masculina. $C$ abe además subrayar que las variables que más influyen en el uso del intercambio de favores son la categoría socio profesional y el nivel educacional, debido a su importancia en la constitución misma del capital social. Se puede establecer una tipología de la clase media en función de estas variables (véase Barozet, 2002).

${ }^{39}$ En el informe del PN U D del 2000, se establece que del total de actividades asociativas a nivel nacional, solamente un 3\% corresponde a la vida partidista (PN U D , 2000).

${ }^{40} \mathrm{La}$ densidad de una red corresponde a la proporción de vínculos existentes, en comparación con los vínculos posibles. A cambio, la multiplejidad de refiere a la variedad de vínculosque se establecen entre dospersonas (un colega puede ser a la vez un amigo, 0 un familiar, etcétera). 
los círculos sociales, lo que a su vez conlleva una mayor densidad de la red. Según los análisis de redes, a mayor densidad y multiplejidad de la red, menos diversa es la información que circula en ella, lo que podría atentar contra la capacidad de los miembros de los grupos medios para conseguir bienes y servicios diversificados. Sin embargo, este elemento se complementa en parte por otra característica central del intercambio de favores y que explica su particular eficiencia en términos de integración: su carácter transitivo. En las palabras de una de las entrevistadas, «cuando no tienes un pituto directo, buscas a alguien que tienen uno».41 La transitividad es sin lugar a dudas uno de los elementos más llamativos del intercambio de favores, pues permite aumentar o ampliar los círculos sociales a los cuales se puede tener acceso, a la vez que refleja y extiende la solidaridad orgánica del grupo medio.

La eficiencia del intercambio de favores sigue particularmente notable hoy en la obtención de trabajos de parte de los miembros de los sectores medios, por lo demás uno de los elementos vitales del desempeño social. En este aspecto, el uso del intercambio de favores es más que central: es obligatorio, pues es necesario que exista un vínculo - aunque mediatizado por una tercera personapara que pueda existir una base de confianza entre empleador y empleado. Cualquiera sea el medio profesional, la regla es la misma: el reclutamiento no funciona solamente sobre la base de las competencias del postulante. Toma en cuenta un conjunto de criterios sociales y relacionales que pesan muchas veces más que la formación de la persona y conforma una cultura laboral que opera incluso en las grandes empresas o en las filiales extranjeras en $\mathrm{C}$ hile. ${ }^{42}$

Desde el punto de vista teórico, los vínculos por los cuales transitan los favores son flexibles y basados en una ideología del don y del contra don 0 economía simbólica (M auss, 1960[1924]; Bourdieu, 1980) altamente eficiente, que determina una deuda simbólica y favorece en el tiempo la permanencia ritual de los vínculos, al sellar la obligación de reciprocidad. Lo interesante del intercambio de favores es que no se limita al intercambio puntual de un favor: el intercambio de favores puede ser descompuesto en una fase de don y una fase de reciprocidad. Dichas fases repetidas y ritualizadas, construyen en el tiempo una relación social particular, inscrita en un grupo social determinado, la consolida y liga finalmente un gran número de individuos gracias a su transitividad. Se trata de un mecanismo que favorece la cohesión social, otorgando a las vin-

${ }^{41}$ Entrevista con Jimena, jubilada, 65 años.

42 Incluso en las empresas o agencias públicas en las cuales existe un servicio de recursos humanos cuya misión consiste supuestamente en reclutar sobre la base de competencias específicas, mostramos gracias a varias semanas de observación participante en dichos servicios (en una universidad privada de prestigio, una municipalidad y la Presidencia de la R epública), que existen sesgos en la difusión de la información cuando se necesita contratar a una persona. Por lo tanto, las personas que postulan recibieron la información por medio de sus conocidos, lo que restringe absolutamente el universo de postulantes, pero mantiene una apariencia de reclutamiento objetivo, incluso a ojos de los propios reclutadores. Se podría considerar como una versión aún más cerrada de la descripción realizada por $G$ ranovetter en Estados U nidos (G rcanovetter, 1974). 
culaciones un contenido a la vez afectivo, simbólico y utilitario, que da cuenta de la complejidad de toda relación social. Permite además superar una de las dificultades clásicas que enfrentan las ciencias sociales: el don y el contra don alían la libertad que tiene el individuo de intercambiar lo que quiere con quien quiere y la satiffacción de las necesidades de los demás para satiffacer las suyas.

Pero lo notable en el caso del intercambio de favores en $C$ hile, es que se trata de una práctica que no está completamente objetivada. Si bien se habla del «pituto», su peso respecto a la trayectoria personal no es dimensionado. La relativa invisibilidad de este fenómeno se debe en gran parte al hecho que asumirla significaría reconocer la existencia de prácticas y lógicas poco compatibles con la imagen de un país económicamente exitoso a nivel internacional y que funciona en base a un modelo neoliberal. De hecho, el discurso acerca del intercambio de favores se construye poco a poco en las entrevistas que hemos realizado, mientras el entrevistado lo va objetivando, ${ }^{43}$ pero no existe de buenas a primeras un discurso so bre este objeto social. En efecto, la práctica se observa en la vida cotidiana, pero no es el objeto de un discurso socialmente construido. Este punto es congruente con el análisis de Bourdieu: «El intercambio de dones es uno de los juegos sociales a los cuales se puede jugar solamente cuando los jugadores no quieren conocer y sobre todo no quieren reconocer la verdad objetiva del juego, la que muestra el modelo objetivante y segundo cuando están dispuestos a contribuir, mediante sus esfuerzos, sus cuidados, sus atenciones, su tiempo a la producción del desconocimiento colectivo»(1980: 179).

En los grupos sociales estudiados en esta investigación y en las entrevistas realizadas, no se ha encontrado sujeto al guno que no practique el intercambio de favores. Q uienes lo usan poco suelen tener un capital social extremadamente reducido, lo que conlleva en una rápida degradación del capital económico, debido a que el acceso a un empleo también depende del intercambio de favores. Por lo demás, quien se niega a devolver un favor sale rápidamente de la lista de «amigos» de quien solicitó el favor, en especial si se sabe que puede satisfacer la demanda. La negativa a honrar la reciprocidad lleva inmediatamente a la

${ }^{43}$ Es interesante notar que en las entrevistas, la lógica del discurso de los entrevistados de clase media suele ser la siguiente: 1) una fase bastante larga de descripción de situaciones de intercambio de favores de parte de otras personas que han conseguido ventajas, en un tono de crítica; 2) una breve fase de toma de conciencia de que esta práctica está muy presente también en los círculos sociales cercanos al entrevistado; 3) la tercera fase que lleva a la toma de conciencia de que el entrevistado también recurre a esta práctica; ahí empieza la narración en forma más personalizada donde abundan las justificaciones acerca de la «necesidad» de recurrir al intercambio de favores para solucionar situaciones difíciles de la vida cotidiana y sobre el deber de solidaridad entre pares; 4) la cuarta y última etapa corresponde a la toma de conciencia de que el intercambio de favores ha tenido un peso muy importante en el recorrido laboral de la persona, incluso más que sus «méritos propios», lo que genera dos tipos de consecuencia: a) la «depresión» cuando se mide las consecuencias de este fenómeno a nivel macro social o b) la valoración del papel de la solidaridad y de la ayuda en el grupo. $\mathrm{N}$ o todos los entrevistados llegan a la cuarta fase (solamente la cuarta parte de la muestra). La mayoría se queda en la primera o la tercera etapa. 
retrogradación a la periferia de la red y a calificar a la persona de malagradecida y poco solidaria, pero por lo observado, la negación de la reciprocidad es poco común, pues pone en peligro el edificio personal y grupal sobre el cual descansa el acceso de los grupos mesocráticos a un gran número y variedad de recursos. $Y$ en otro plano, negarse a hacer un favor significa reconocer que no se tienen las vinculaciones adecuadas para este fin, lo que denota una red pobre y poco eficiente y por lo tanto, poco prestigio. En efecto, en la escala del prestigio social, el intercambio de favores tiene un lugar específico y ayuda a entender porque los chilenos y chilenas de clase media son propensos a ayudar a sus semejantes: mientras más importante o difíciles de conseguir, más valorados los favores y más fuerte la obligación de reciprocidad. Esto permite comprender por qué un mayor capital social no solamente implica un mayor prestigio social, sino que a cambio, un mayor acceso a la devolución de favores. Es común de hecho en las conversaciones cotidianas de los integrantes de las clases medias mencionar en forma regular a las personas conocidas, en especial cuando ocupan una posición ventajosa en la estructura social o en el grupo de conocidos. Este rasgo está muy marcado en las conversaciones en las cuales dos personas recién se están conociendo y busca, en la presentación de sí mismo, dar al otro una imagen de su ubicación en la red gracias a su capital social.

El intercambio de favores es una práctica históricamente arraigada en C hile: incluso funciona como una institución y remite a la estructuración de la confianza en el país. Es por esta razón que no se puede abordar el intercambio de favores solamente desde la perspectiva económica o de la menor competencia que tiene la economía chilena por usarlo como forma de reclutamiento, ${ }^{44}$ pues si bien afecta la productividad general del país, ofrece a la vez una muy eficiente red de integración y de protección a la cual es muy difícil querer renunciar en pos de la mayor competitivad del país: la lógica de la ayuda prevalece sobre la lógica económica, ${ }^{45}$ aunque los chilenos y chilenas también se quejen con frecuencia del mal funcionamiento de las administraciones privadas y públicas, debido a que están pobladas en gran parte de personas con un bajo nivel de exigencias y que suministran sus servicios so bre la base de la presión que ejercen personas determinadas, en detrimento de la justicia social y de la justicia a secas. ${ }^{46}$ La elección racional no parece entonces ser aquí la mejor manera de entender el intercambio de favores, pues se trata de un fenómeno anclado profundamente en las conciencias y en las prácticas, a tal nivel que el hecho de no tener un contacto en un lugar determinado desmotiva inmediatamente a la persona que quiere conseguir algo de ahí, como si fuera más fuerte la sensación de que sin intercambio de favores, todos los esfuerzos son inútiles.

${ }^{44}$ «A planar la cancha con más competencia», como se sugiere en N avia y Engel, 2006.

${ }^{45}$ Existe sin embargo una limitación: si se ayuda a colocar a una persona en un empleo, esta persona debe responder a las expectativas de quien la emplea y de quien la recomendó: cabe estar a la altura del favor hecho.

${ }^{46}$ C omo lo demostraron N úñez y G utiérrez (2004) respecto de la relación entre origen de clase y valor del diploma para encontrara trabajo en $\mathrm{C}$ hile. 


\section{Conclusión}

$\mathrm{H}$ istóricamente, el Estado chileno ha funcionado sobre la base de favores y no de derechos. A unque hoy en día esta afirmación ya no es solamente válida para la función pública, sino que también en el sector privado, en esta articulación se forja parte de los vínculos y de la cultura relacional de las clases medias. En este universo, el capital social es un recurso altamente estratégico para este grupo social. De hecho, varias publicaciones en los últimos años han enfatizado el mayor individualismo en Chile, según una tendencia general de los estudios sociológicos: hablan de una «erosión del vínculo social» en este país y en otros. $\mathrm{N}$ o obstante, vemos aquí que el intercambio de favores es una práctica incluyente y estructurante, pues ayuda a la permanencia en el tiempo de vínculos sociales y a la búsqueda - aunque no sea consciente- de nuevas vinculaciones.

Parte de la riqueza de la práctica aquí estudiada radica en que existe entre la esfera pública y el espacio del mercado un amplio ámbito de regulación social que no tiene que ver ni con la acción pública ni con la acción económica. Existen transacciones, como el intercambio de favores, que se construyen en relación con la estructura estatal o privada, se alimentan de ella y construyen una red muy eficiente de ayuda informal. Se trata de una práctica sistemática, que descansa en redes horizontales más bien amistosas y en vínculos de confianza. Permite obtener un gran número de bienes y servicios no disponibles por las vías más formales o más instituciones y en el caso de Chile, se trata casi de la única forma de obtener un trabajo. Finalmente, es valorada por los chilenos y chilenas, en la medida que ofrece una protección y una seguridad que dependen más del capital social que del capital económico, elemento particularmente valorado hoy en Chile por quienes no logran escapar definitivamente de cierta vulnerabilidad social.

Anexo 1.Empleo en el sector centralizado, por funciones (en miles de personas)

\begin{tabular}{|c|c|c|c|c|c|c|c|c|}
\hline & \multicolumn{4}{|c|}{ Servicios administrativos } & \multirow{2}{*}{$\begin{array}{l}\text { Servicios } \\
\text { sociales }\end{array}$} & \multirow{2}{*}{$\begin{array}{l}\text { Entidades } \\
\text { de fomento }\end{array}$} & \multirow{2}{*}{$\begin{array}{l}\text { Empresas } \\
\text { estatales }\end{array}$} & \multirow[b]{2}{*}{ Total } \\
\hline & Generales & Económ. & Sociales & Total & & & & \\
\hline 1940 & 24,2 & 3,5 & 0,8 & 28,5 & 15,4 & 0,1 & 3,7 & 47,7 \\
\hline 1946 & 26,9 & 6,9 & 1,0 & 34,8 & 24,5 & 0.6 & 4,3 & 64,2 \\
\hline 1952 & 29,2 & 9,3 & 1,0 & 39,5 & 30,5 & 0,5 & 6,1 & 76,7 \\
\hline 1958 & 30,2 & 9,5 & 0,8 & 40,6 & 37,7 & 2,5 & 6,6 & 87,4 \\
\hline 1964 & 35,4 & 13,1 & 1,2 & 49,7 & 48,0 & 3,1 & 9,8 & 110,7 \\
\hline 1970 & 37,4 & 14,3 & 2,9 & 54,6 & 74,1 & 7,1 & 11,7 & 147,5 \\
\hline \multicolumn{9}{|c|}{ Tasas de crecimiento anual } \\
\hline $1940-1946$ & 1,8 & 12,0 & 3,8 & 3,4 & 8,0 & 34,8 & 2,5 & 5,1 \\
\hline 1946-1952 & 1,4 & 5,1 & 0,0 & 2,1 & 3,7 & - & 6,0 & 3,0 \\
\hline 1952-1958 & 0,6 & 0,3 & - & 0,4 & 3,6 & 30,8 & 1,3 & 2,2 \\
\hline $1958-1964$ & 2,7 & 5,5 & 7,0 & 3,4 & 4,1 & 3,6 & 6,8 & 4,0 \\
\hline $1964-1970$ & 0,9 & 1,5 & 15,8 & 1,6 & 7,5 & 14,8 & 3,0 & 4,9 \\
\hline $1940-1970$ & 1,5 & 4,8 & 4,4 & 2,2 & 5,4 & 15,3 & 3,9 & 3,8 \\
\hline
\end{tabular}

Fuente: Muñoz, Gatica y Romaguera (1980: 15). 
Anexo 2. Gasto público del sector social, 1935-1983

\begin{tabular}{|c|c|c|c|c|c|c|}
\hline \multirow[t]{2}{*}{ Año } & \multicolumn{2}{|c|}{ Gasto público social } & \multicolumn{4}{|c|}{ Composición de los gastos públicos (\% del gasto social) } \\
\hline & $\begin{array}{c}\text { Billones de } \\
\text { pesos de } 1981\end{array}$ & $\%$ del PNB & $\begin{array}{c}\text { Salud, } \\
\text { seguridad } \\
\text { social y trabajo }\end{array}$ & Previsión & $\begin{array}{l}\text { Vivienda y } \\
\text { urbanismo }\end{array}$ & Educación \\
\hline $1925^{*}$ & 3,1 & 2,1 & & & & \\
\hline 1935* & 12,3 & 5,2 & & & & \\
\hline 1945* & 23,3 & 8,0 & & & & \\
\hline 1955 & 55,1 & 14,9 & 17,9 & 41,4 & 20,4 & 20,3 \\
\hline 1961 & 85,4 & 17,0 & 18,9 & 51,4 & 11,5 & 18,1 \\
\hline 1963 & 90,4 & 16,3 & 20,1 & 46,6 & 15,1 & 18,2 \\
\hline 1965 & 124,2 & 20,0 & 18,0 & 45,5 & 17,9 & 18,6 \\
\hline 1967 & 159,5 & 20,1 & 15,7 & 46,0 & 17.8 & 20,6 \\
\hline 1969 & 180,8 & 18,7 & 16,2 & 43,6 & 17,8 & 22,4 \\
\hline 1970 & 206,9 & $19,9^{1}$ & 16,4 & 45,2 & 16,0 & 22,4 \\
\hline 1971 & 274,4 & 25,2 & 15,8 & 45,9 & 16,3 & 21,9 \\
\hline 1972 & 226,2 & 25,8 & 16,8 & 44,4 & 15,9 & 23,0 \\
\hline 1974 & 182,6 & 17,6 & 16,2 & 36,6 & 21,5 & 25,7 \\
\hline 1975 & 153,2 & 18,3 & 18,0 & 41,9 & 15,7 & 24,4 \\
\hline 1977 & 165,8 & 17,4 & 20,3 & 40,4 & 13,4 & 25,9 \\
\hline 1979 & 191,7 & 15,4 & 19,4 & 44,2 & 9,9 & 26.6 \\
\hline 1981 & 202,1 & 14,3 & 21,8 & 43,4 & 9,4 & 25,3 \\
\hline 1983** & 206,1 & 17,1 & 24,6 & 47,1 & 5,3 & 23,0 \\
\hline
\end{tabular}

${ }^{1}$ Según el autor, esta cifra es la más elevada de América Latina para ese año y es comparable al promedio de los países de la OCDE (26,9\% del PNB en Alemania, 25,7\% para Francia, 19\% para Finlandia, 10,3\% para Estados Unidos, $13,2 \%$ para J apón).

* Cifras levemente sobrevaluadas (no incluyen las leyes especiales ni los otros ingresos de las instituciones centrales).

** Provisorio [ en el momento de la redacción].

Fuente: Arellano (1984: 33).

\section{$R$ eferencias}

An GelL,A. (1974). Partidospolíticosy movimiento obrero en Chile.M éxico: Era.

A R ELLAN O,J.P. (1985). Políticas socialesy desarrollo. Chile 1824-1984. Santiago:CIEPLAN .

BAROZET,E. (2002). L'échange de faveursau sein descouchesmoyenneschiliennes del'entraide informelle à la régulation sociale. París, EH ESS. Inédito.

BO U R DIEU , P. (1980). Le senspratique. París. M inuit.

DIDIER, M arcelo. (1986). R edes socialesy búsqueda de ayuda. $R$ evista C hilena de Psicología(1): 3-7.

ESPIN OZA,Vicente. (1995). R edes sociales y superación de la pobreza. $R$ evista deTrabajo Social, 66: 31-44.

FILGUEIR A,C. (1976). Expansión educacional y estratificación social en A mérica Latina, 19601970:. BuenosAires: C epal.

FILGU EIR A,C.y C. G EN ELETTI. (1981). Estratificación y movilidad ocupacional en A mérica Latina. Santiago: C epal. 
Faletto, E. y E. R UIz. (1970). Conflicto político y estructura social. En Chile, hoy. Santiago: Siglo Veintiuno.

FLEET , M . (1985). The rise and fall of the chilean christian democracy. Princeton:Princeton U niversity Press.

GAR CÍA COVAR RU BIAS,J. (1990). EI Partido R adical y la clasemedia. La relación de intereses entre 1888 y 1938. Santiago:Andrés Bello.

GAR R ETÓ N , M .A. (1987). R econstruir la política.Transición y consolidación democráticaen Chile. Santiago:Andante.

Go GGM AN ,E. (1974[1967]). Les rites d'interaction. París:É ditions de M inuit.

Gr aCIAR EN A,J. (1967). Poder y clasessocialesen A mérica Latina. BuenosAires: Paidós.

GR AN OVETT ER , M . (1974). G etting ajob.A study of contacts and careers. C ambridge: $H$ arvard U niversity Press.

- . (1982).T he strengh of weak ties.A network theory revisited. En N . Lin y P. M ardsen, Social structure and network analysis C alifornia: Sage Publications.

Jo BEт ,J.C. (1951). Ensayo crítico del desarrollo económico-social de Chile.Santiago:U niversitaria.

Jo H N SO N J. (1958). Political change in LatinA merica.T he emergence of the middle sectors. Stanford: Stanford U niversity Press.

$\mathrm{KOCH}, \mathrm{M}$. (1999). Changes in chilean social structure. Class structure and income distribution between 1972 and 1994. European $R$ eview of LatinA merican and C aribbean Studies, 66.

LAVAU D,J.P. (1976). C ompérage, stratification sociale et rapportsde pouvoir : une enquête à LaPaz. Cahiers desA mériques Latines, 13-14: 103-125.

LO M N IT Z, L. (1994). El compadrazgo, reciprocidad de favores en la clase media urbana de C hile. En $R$ edessociales, cultura y poder: ensayos de antropología latinoamericana M éxico: Flacso.

LOM NITZ,L.YA.M ELNICK.(1991).Chile'smiddle classA struggle in the face of neoliberalism. Boulder y Londres: Lynne R ienner Publishers.

- . (1998). Lacultura políticachilenay los partidosde centro. U naexplicación antropológica. Santiago: Fondo de Cultura Económica.

M ARTín EZ, J. y E,T IRON I. (1985). Las clases sociales en Chile. Cambio y estratificación, 1970-1980. Santiago: Sur.

M AU SS, M . (1960[1924]). Essai sur le don. Forme et rai son de l'échange dans les sociétés archäques. En Sociologie et anthropologie. París. PU F.

M ÉN DEZ, M . L. (2002). Experiencias y Significados asociados a la idea de movilidad social en el relato de doce familias floridanas. $R$ evista $M$ ad, 6 (D epartamento de A ntropología de la U niversidad de C hile). Disponible en <http:/ / sociales.uchile.cl/ publicaciones/ mad/ 06/ paper07.pdf>.

M IR AN DA, E. (editor).(1994). La salud en Chile. Evolución y perspectivas Santiago: C entro de Estudios Públicos.

M UÑ OZ, O.,J. GATICA Y P. R O M AGU ER A. (1980). C recimiento y estructura del empleo estatal en Chile (1940-1970), Santiago: CIEPLAN .

N AVIA, P. y P. EN GEL. (2006). Q ue gane el «más mejor». Santiago: D ebate.

N Ú Ñ EZ, I. (1986). G remios del magisterio. Setenta años de historia. 1900-1970. Santiago: Programa Interdisciplinario de Investigaciones en Educación (PIIE).

N Ú Ñ EZ, R . y J.G UT IÉR R EZ. (2004). Classism, discrimination and meritocracy in the labor market.T he case of C hile. Santiago: U niversidad de C hile, Facultad de CienciasEconómicas y Sociales, D epartamento de Economía (D ocumento de trabajo, 208).

PInTO ,A . (1962). Chile: un caso de desarrollo frustrado Santiago: U niversitaria. 
PIN TO ,A y otros. (1972). Chile, hoy. M éxico: Siglo XXI.

PN U D. (1998). Desarrollo humano en Chile:Lasparadojasdelamodernización. Santiago:PNU D. - . (2000). D esarrollo humano en Chile: M ássociedad para gobernar el futuro. Santiago:PN UD. R HER EM ,A. (2001). Clientelismo político y reforma del Estado en Chile. Santiago:C entro de Estudios Públicos (D ocumento deTrabajo, 305).

R EM M ER ,K. (1984). Party competition in Argentinaand Chile. Political recruitment and public policy, 1890-1930. Londres: U niversity of $\mathrm{N}$ ebraska Press.

SU N KEL, O svaldo. (1971). C ambio social y frustración en C hile. En H . Godoy, Estructura social de C hile (pp.522-536). Santiago: U niversitaria.

TIRON N,E. (1998). El régimen autoritario. Parauna sociologíade Pinochet. Santiago:D olmen.

U R ZÚ AV A LEN ZU ELA, G. (1968). Lospartidospolíticoschilenos. Lasfuerzaspolíticas. Ensayos de insurgencia política en Chile. Santiago:Editorial Jurídica de C hile.

U R ZÚ AVALEN ZUELA, G.yA.GAR CíA BAR ZELATTO. (1971). Diagnóstico de la burocracia chilena (1818-1969). Santiago: Editorial Jurídica de C hile.

V ALEN ZU eLA,A. (1977). Political brokersin Chile:Local government and centralized policy. Durham: D uke U niversity Press. 